Editorial

\title{
Metodologias e aplicações inovadoras em Sistemas e Tecnologias de Informação (STI)
}

\section{Innovative Methodologies and Applications in Information Systems and Technologies (IST)}

\author{
João Vidal Carvalho ${ }^{1}$, António Abreu ${ }^{1}$, Álvaro Rocha ${ }^{2}$ \\ cajvidal@iscap.ipp.pt, aabreu@iscap.ipp.pt, amrocha@dei.uc.pt \\ ${ }^{1}$ Politécnico do Porto/ISCAP/CEOS.PP, Rua Jaime Lopes Amorim, s/n, 4465-004 S. Mamede de Infesta, \\ Portugal. \\ ${ }^{2}$ Universidade de Coimbra, Departamento de Engenharia Informática, Pólo II - Pinhal de Marrocos, 3030- \\ 290 Coimbra, Portugal.
}

DOI: 10.17013/risti.25.0

\section{Introdução}

No contexto atual de extrema competitividade, a inovação é um desafio permanente para todas as organizações, independentemente da sua área de negócio ou sector de atividade. A gestão da inovação é tão importante quanto fundamental, para uma organização que aposta na melhoria contínua e que ambiciona criar valor para os clientes e/ou colaboradores. Na verdade, as inovações no âmbito das STI são, não raras vezes, o motor para levar as organizações ao sucesso e para as manter na vanguarda perante os seus concorrentes.

A inovação nos STI, surge como um domínio estratégico de investigação para suportar as organizações através de todo o processo de desenvolvimento e crescimento. A adoção de metodologias e aplicações inovadoras nos STI, devem naturalmente, começar através de um processo criativo de identificação de oportunidades e necessidades da sociedade, prosseguindo para o seu desenvolvimento e implementação, até desencadear na criação de valor e consequentemente na melhoria da eficácia, eficiência e desempenho das organizações.

Neste enquadramento, o número vinte e cinco da RISTI (Revista Ibérica de Sistemas e Tecnologias de Informação) debruça-se sobre um conjunto diversificado de metodologias e aplicações inovadoras em Sistemas e Tecnologias de Informação, que vão desde a análise de dados, passando por modelos de aprendizagem, até às aplicações web. 
O conjunto de oito artigos publicados neste número da RISTI, resultou de um escrutínio exímio efetuado pelos membros da comissão científica sobre os quarenta e seis trabalhos apresentados pelos autores, oriundos treze do Brasil, sete de Portugal, seis da Colômbia, seis do Equador, cinco da China, dois de Espanha, dois de Cuba, dois do Peru, um do Chile, um do México e um de França, correspondendo a uma taxa de aceitação de $17 \%$.

\section{Estrutura}

Para facilitar a leitura desta edição, optou-se por apresentar em primeiro lugar, as contribuições que apresentam estudos associados à análise de dados. Posteriormente, apresentam-se estudos sobre o processo de aprendizagem. Finalmente, os últimos artigos, embora se apresentem como altamente inovadores, são de âmbito mais genérico. Assim:

- No primeiro artigo, os autores apresentam um sistema multiagente que tem como objectivo ir além da captura das transações suspeitas de Branqueamento de Capitais, auxiliando o especialista humano na análise das suspeições. Os agentes criados neste artigo, utilizam técnicas de data mining para criação de perfis de comportamento transacional; aplicam regras obtidas na aprendizagem, em conjunto com regras especificas baseadas em aspectos legais e nos perfis criados para captura de transações suspeitas; e analisam estas transações sinalizadas indicando ao especialista humano, aquelas que necessitam de análise mais detalhada.

- O segundo artigo, expõe inicialmente de forma breve, as formas de análise estatística de dados textuais, bem como análises qualitativas comumente usadas em ciências sociais. Numa fase posterior, é proposto um novo tratamento de dados para poder usar ambos os modos de análise de forma combinada, ao trabalhar com vários textos simultaneamente. $\mathrm{O}$ artigo detalha um procedimento no qual o Dual STATIS e o JK-Meta-Biplot são usados, técnicas multivariadas que representam graficamente uma nuvem pontual multidimensional num espaço de dimensão reduzida, para representar a estrutura de consenso de diferentes participações num questionário qualitativo.

- O terceiro artigo, descreve um estudo que propõe um modelo explicativo que incorpora as cinco dimensões da personalidade CANOE (Conscientiousness, Agreebleness, Neuroticism, Openess to Experience, Extroversion) e o fluxo, como determinantes na adoção de um curso online de programação gamificada. O estudo foi conduzido com uma amostra de alunos universitários, e o modelo explicativo foi validado usando a modelação de equações estruturais. Os resultados obtidos neste estudo, são um contributo para a compreensão dos determinantes na adoção de cursos online gamificados.

- O artigo seguinte, expõe um projeto que pretende identificar, analisar e descrever alguns métodos existentes para melhorar a acessibilidade dos ambientes virtuais de aprendizagem. Para isso, procedeu a uma revisão sistemática da literatura sobre acessibilidade nestes ambientes, entre 2010 e 2016. Concluiu que, a combinação de vários métodos com base em padrões e normas é decisiva para apoiar serviços personalizados de ensino/aprendizagem. Além disso, o "Universal Design for Learning" e o "Universal Design of Instruction," fornecem um conjunto de princípios e estratégias que procuram reduzir as barreiras e criar modelos facilitadores de ensino/aprendizagem. 
- No quinto artigo, os autores desenvolvem uma prova a partir da Taxonomia de Bloom, que permite comparar o desempenho dos alunos, independentemente da linguagem de programação com que iniciaram a sua aprendizagem. A prova apresenta questões de escolha múltipla para os quatro níveis iniciais e questões de desenvolvimento para os dois últimos níveis. Após a sua construção, a prova foi validada por 12 especialistas e submetida a um grupo-piloto para analisar a fiabilidade e dificuldade dos itens. Os resultados obtidos demonstram que a prova é válida, fiável e discriminativa.

- No sexto artigo, é desenvolvida uma proposta que visa auxiliar os conselhos executivos de qualquer comité local da AIESEC, a avaliar os seus planos anuais, bem como as decisões estratégicas mais importantes no desenvolvimento da sua gestão. Na referida proposta, duas ferramentas são integradas no nível organizacional, ou seja, o Balanced Scorecard (BSC) e a dinâmica dos sistemas. O BSC é usado como ferramenta que permite que cada membro da organização seja claro sobre os objetivos e atividades que permitirão o cumprimento do planeamento proposto, e a dinâmica dos sistemas é usada como uma ferramenta que permitirá que o BSC seja analisado de forma flexível.

- No sétimo artigo, são detalhadas a análise e aplicação de metodologias ágeis e tecnologias de código aberto, no desenvolvimento de uma aplicação web e móvel para automatizar e controlar a frota automóvel da Universidade Técnica Particular de Loja (UTPL). Entre as funções essenciais da aplicação, salienta-se a gestão e manutenção dos veículos assim como a gestão de empréstimos dos mesmos. Como contribuição adicional, a construção do aplicativo móvel inclui as mesmas qualidades funcionais dos aplicativos web, facilitando a interação e usabilidade com base no tempo e lugar onde a pessoa se encontra.

- No último artigo, através da revisão sistemática da literatura, verificou-se que as teorias mais relevantes que os autores adotam nas suas investigações relacionadas com o cumprimento das políticas de segurança, estão focadas na compreensão do comportamento humano através de teorias psicológicas ou sociais, traduzindo-se numa abordagem interdisciplinar que permite uma visão global do ponto de vista tecnológico e de outras disciplinas, conduzindo a uma abordagem real do problema.

\section{Agradecimentos}

Termina-se esta introdução, expressando o nosso agradecimento a todos os autores e revisores envolvidos nesta edição, esperando que este número da RISTI se revele uma leitura profícua para todos os que se mobilizam em torno da problemática dos Sistemas e Tecnologias de Informação. Um agradecimento especial à AISTI, proprietária e promotora da RISTI, à Academic Journals Database, CiteFactor, Compendex, Dialnet, DOAJ, DOI, EBSCO, GALE, IndexCopernicus, Index of Information Systems Journals, ISI Web of Knowledge, Latindex, ProQuest, QUALIS, SciELO, SCImago e Scopus, entidades que têm contribuído para tornar a RISTI uma referência neste competitivo mercado das revistas científicas. 